\title{
Predicting and Analyzing E-Logistics Demand in Urban and Rural Areas: An Empirical Approach on Historical Data of China
}

\author{
Lijuan Huang, Guojie Xie*, Dahao Li, and Chunfang Zou \\ School of Management, Guangzhou University, Guangzhou, 510000, China
}

\begin{abstract}
With the rapid development of the e-commerce economy in urban and rural areas, China's logistics industry has entered a stage of transformation and upgrade. First, this paper introduces the Supply-Chain Operations Reference-model as a theoretical reference for index selection. Then, after comparing the BP neural network and linear regression analysis, we chose the BP neural network analysis method, which is more stable and accurate in forecasting e-logistics demand scale in urban and rural areas. Finally, according to the results of the data analysis, this paper divides the development of e-logistics demand in urban and rural areas into two stages and discusses the reasons for the formation of these two stages in detail. This job not only provides a new perspective for the study of rural e-commerce and urban and rural e-logistics demand prediction, but also provides a theoretical reference for the formulation of government policies and farmers' participation in rural e-commerce.
\end{abstract}

Keywords: SCOR model; BP neural network; e-logistics demand in urban and rural areas; prediction

(Submitted on March 30, 2018; Revised on May 2, 2018; Accepted on June 9, 2018)

(C) 2018 Totem Publisher, Inc. All rights reserved.

\section{Introduction}

In recent years, China's e-commerce has experienced an unprecedented period of development. As a digital business pattern, e-commerce has become one of the main development forms between modern commerce and trade [7]. The new e-commerce trends continue to emerge, such as online and offline multi-party cooperation, uplink of agricultural products, and e-commerce infiltrates to lower-tier cities [12]. Under this background, the demand for e-logistics in urban and rural areas through all the provinces shows a great growth trend, and the traditional e-logistics system faces new challenges [6]. Thus, the forecast and analysis of logistics demand according to the relevant data of e-logistics in urban and rural areas is of great significance for the evaluation of the previous policies and the formulation of future policies.

The study found that both at home and abroad, the current situation of logistics demand in urban and rural areas is mainly focused on the analysis of influencing factors, performance evaluation, and prediction under different methods. In the analysis of influencing factors: Yang and Wang [19] proposed that the size of logistics demand in the future can be reflected by prediction of the total freight based on the influencing factors, including first industrial output, second industrial output, third industrial output, gross output values of agriculture and total population. Chen et al. [2] divided the logistics demand to forecast into three parts: the agricultural logistics demand, the manufacturing logistics demand and the enterprise logistics demand. Yin et al. [20] selected the total freight volume to represent logistics demand and discussed the relationship between logistics and indicators of economic and social development from the perspective of macroeconomics. Sun et al. [15] expressed the logistics demand with a turnover of freight traffic, and selected the first industrial output, the second industrial output, and the third industry value as indicators affecting the logistics demand in Northeast China. In the performance evaluation, Yogi [17] took India manufacturing enterprises as an example, and proposed a framework to evaluate the demand and network of reverse logistics. Jane [5] combined the delivery cost and delivery reliability as the performance evaluation index of the logistics demand system. Cheung and Hausman [3] proposed a two-echelon inventory system, which is supplied from a single supplier to multiple retailers. Under this system, each retailer can set a unique quantity of purchase as a multiple of the basic packing

\footnotetext{
* Corresponding author.

E-mail address: xieguojie@e.gzhu.edu.cn
} 
size. Feng et al. [4] incorporated dynamic and collaborative thinking into the evaluation model of supply chain logistics capability, and they discussed the correlation between the five factors of logistics operation: supply chain relationship management, dynamic integration, customer service and supply chain logistics coordinated with supply chain logistics capability. Analysis on different methods of forecasting: Li and Liu [10] analyzed the change regulation of logistics demand in seven cities of Chengdu, Shenzhen, Nanjing and so on by analogy analysis, proportion conversion and correlation analysis methods. Ya [18] analyzed China's cold chain logistics demand by multiple regression and the AW-BP prediction method. Si et al. [16] believed that the improved grey model can improve the accuracy of logistics demand forecasting. Nikolopoulos et al. [13] proposed the application of a neural network method to predict the scattered demand in logistics supply chain management by a large amount of data simulation.

In summary, previous studies mostly studied the influence factors and performance evaluation of logistics demand scale in a single way, lacking the combination of theoretical basis and empirical method. Especially in the selection of evaluation index and data processing, there is no comprehensive, scientific and rational use of qualitative and quantitative methods, so the selected indicators cannot better reflect the actual situation of logistics demand scale and the data processing results are not reliable. Therefore, this paper has two innovations: first, the SCOR model is introduced as the theoretical basis of the study, which can give guidance on selecting effective indexes that reflect the e-logistics demand scale in urban and rural areas. Second, a BP neural network algorithm is used to simulate the historical data of selected indexes and compares the data with a linear regression model. On this basis, we select the least error model to predict China's future e-logistics demand scale in urban and rural areas. The theory and methods presented in this paper are taken into full account from the complexity of index selection and instability in data processing. The experimental results can be used to evaluate and forecast the e-logistics demand in urban and rural areas.

\section{Theoretical Model and Research Method}

\subsection{SCOR Theoretical Model}

The SCOR model is called the Supply-Chain Operations Reference-model, and it was first put forward by the International Supply-Chain Council. The theoretical model is based on five different management processes, namely planning, purchasing, production, distribution, and return [14]. Generally, it can be divided into a performance measurement index layer, configuration layer, and process element layer. According to the latest SCOR model map published by the American SupplyChain Council, this paper is drawn as shown in Figure 1.

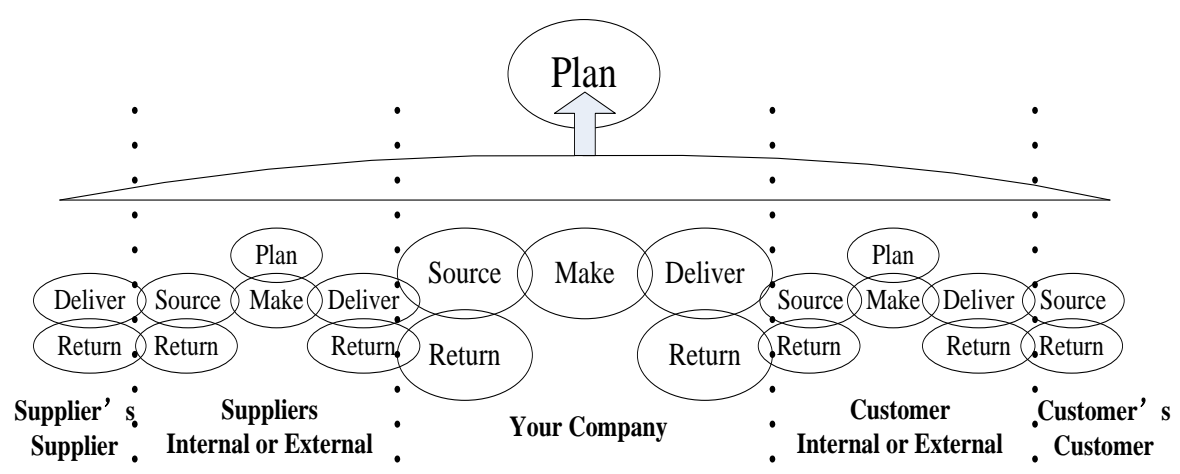

Figure 1. Schematic diagram of SCOR model (Adapted from SCC, 2010 )

As the first standard supply chain process reference model, SCOR is the diagnostic tool of the supply chain. It covers all industries and can be used to describe, measure and evaluate supply chain configuration. Also, the logistics workgroup can be restructured by this model in accordance with the plan, procurement, production, distribution and return [8].

\subsection{Back Propagation Neural Network}

The BP neural network is the Error Back Propagation Algorithm [9]. The architecture of the network was formed by an input layer, one or more hidden layers, and an output layer [11]. Usually, a three layers' BP neural network architecture is shown in Figure 2. 


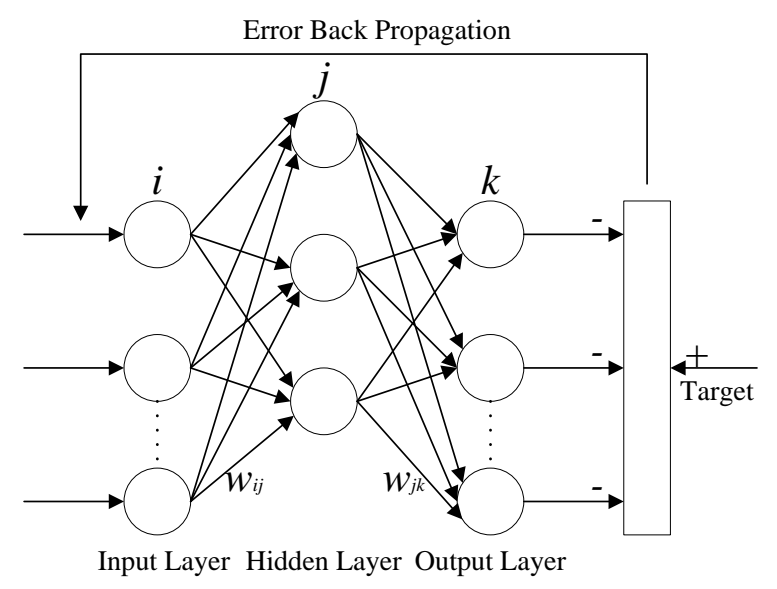

Figure 2. The structure picture of BP neural network

The BP neural network contains more than one hidden layer. It cannot only solve linearly separable problems, but also have the ability to deal with non-linear problems. The mathematical expressions of the hidden layer and the output layer are as follows:

$$
h_{j}=f_{\text {hidden }}\left(\sum_{i=1}^{m} w_{i j} x_{i}\right) Y_{k}=f_{\text {output }}\left(\sum_{j=1}^{n} w_{j k} h_{j}\right)
$$

Where $X=\left(x_{1}, x_{2}, \cdots, x_{i}\right)(i=1,2, \cdots m)$ is the input, $h=\left(h_{1}, h_{2}, \cdots, h_{j}\right)(j=1,2, \cdots, n)$ is the output of hidden layer, $Y=\left(Y_{1}, Y_{2}, \cdots, Y_{k}\right)(k=1,2, \cdots, p)$ is the output, $w$ is the weight matrix between the hidden layer and the output layer, $f_{\text {hidden }}($.$) is the function of hidden layer and f_{\text {output }}($.$) is the function of the output layer [1].$

Determining the number of hidden layer nodes in the neural network design is a very important aspect, and its compute expression is as follows:

$$
\text { hidden nodes }=\sqrt{m+p}+a . a \in[0,10]
$$

Where $n$ is the number of input layers, $m$ is the number of output layers, and $a$ is a constant [1].

\section{Data Analysis}

\subsection{Index Selection and Data Sources}

The SCOR theoretical model is established in five different management processes: planning, procurement, production, distribution and return. In the process of index selection, this paper, according to the segmentation indicators of the five management processes, selects express quantity (X1, ten thousand pieces), the number of internet users (X2, ten thousand people), quantity of employment between urban and rural areas (X3, ten thousand people), consumer price index (X4), gross output value of agriculture, forestry, animal husbandry and fishery (X5, billion yuan) and turnover of freight traffic (X6, million tons per kilometer) as the variables to evaluate and forecast e-logistics demand scale and freight volume (Y, ten thousand tons) as a measure of e-logistics demand scale in urban and rural areas.

Specifically, the plan management process in the SCOR model includes demand and supply plans. So, we select the quantity of employment between urban and rural areas (X3) to reflect the supply plan of enterprises and the consumer price index (X4) to reflect the company's demand plan. The express quantity (X1) is a reflection of the distribution management process in the SCOR model. The number of Internet users (X2) is an indirect reflection of product order confirmation and product return in the process of delivery and return management in the SCOR model. The gross output value of agriculture, forestry, animal husbandry and fishery (X5) reflects the amount of material needed in the process of enterprise production management. Turnover of freight traffic (X6) can indirectly reflect the procurement management process in the SCOR model. 
For the measurement index of the e-logistics demand scale in urban and rural areas, this paper refers to the index selection method of predecessors and chooses the freight volume $(Y)$ to express [2, 19]. The data of these indicators are derived from the China Statistical Yearbook. Table 1 shows the specific data for each indicator.

Table 1. The index data of e-logistics demand scale between urban and rural areas over the years

\begin{tabular}{|c|c|c|c|c|c|c|c|}
\hline Index code & $\mathrm{X} 1$ & $\mathrm{X} 2$ & $\mathrm{X} 3$ & $\mathrm{X} 4$ & $\times 5$ & X6 & $\mathrm{Y}$ \\
\hline 1997 & 6878.9 & 62 & 69820 & 441.9 & 23788.4 & 38384.7 & 1278218 \\
\hline 1998 & 7667.7 & 210 & 70637 & 438.4 & 24541.9 & 38088.7 & 1267427 \\
\hline 1999 & 9091.3 & 890 & 71394 & 432.2 & 24519.1 & 40567.8 & 1293008 \\
\hline 2000 & 11031.4 & 2250 & 72085 & 434 & 24915.8 & 44320.5 & 1358682 \\
\hline 2001 & 12652.7 & 3370 & 72797 & 437 & 26179.65 & 47709.9 & 1401786 \\
\hline 2002 & 14036.2 & 5910 & 73280 & 433.5 & 27390.8 & 50685.9 & 1483447 \\
\hline 2003 & 17237.8 & 7950 & 73736 & 438.7 & 29691.8 & 53859.2 & 1564492 \\
\hline 2004 & 19772 & 9400 & 74264 & 455.8 & 36238.99 & 69445 & 1706412 \\
\hline 2005 & 22880.3 & 11100 & 74647 & 464 & 39450.89 & 80258.1 & 1862066 \\
\hline 2006 & 26988.04 & 13700 & 74978 & 471 & 40810.83 & 88839.85 & 2037060 \\
\hline 2007 & 120189.56 & 21000 & 75321 & 493.6 & 48892.96 & 101418.81 & 2275822 \\
\hline 2008 & 151329.3 & 29800 & 75564 & 522.7 & 58002.15 & 110300 & 2585937 \\
\hline 2009 & 185785.81 & 38400 & 75828 & 519 & 60361.01 & 122133.31 & 2825222 \\
\hline 2010 & 233891.99 & 45730 & 76105 & 536.1 & 69319.76 & 141837.42 & 3241807 \\
\hline 2011 & 367311.08 & 51310 & 76420 & 565 & 81303.92 & 159323.6 & 3696961 \\
\hline 2012 & 568547.99 & 56400 & 76704 & 579.7 & 89453.05 & 173804.46 & 4100436 \\
\hline 2013 & 918674.89 & 61758 & 76977 & 594.8 & 96995.27 & 168013.8 & 4098900 \\
\hline 2014 & 1395925.3 & 64875 & 77253 & 606.7 & 102226.09 & 181667.69 & 4167296 \\
\hline 2015 & 2066636.84 & 68826 & 77451 & 615.2 & 107056.36 & 178355.9 & 4175886 \\
\hline
\end{tabular}

\subsection{Analysis of BP Neural Network}

This paper uses the MATLAB version of $2014 \mathrm{~b}$ to analyze the data from different indicators. P represents the related data of X1, X2, X3, X4, X5 and X6 from 1997 to 2014. T stands for the data of Y from 1997 to 2014. Ptest represents the data of X1, $\mathrm{X} 2, \mathrm{X} 3, \mathrm{X} 4, \mathrm{X} 5, \mathrm{X} 6$ and Y from 1997 to 2015.

First of all, according to the purpose of the preliminary study, we have compiled a language program for data simulation. Then, we put the program into the command window. After repeating the data simulations 30 times, a set of data with the closest average value is selected. We obtained the following graphs (Figure 3 and Figure 4).

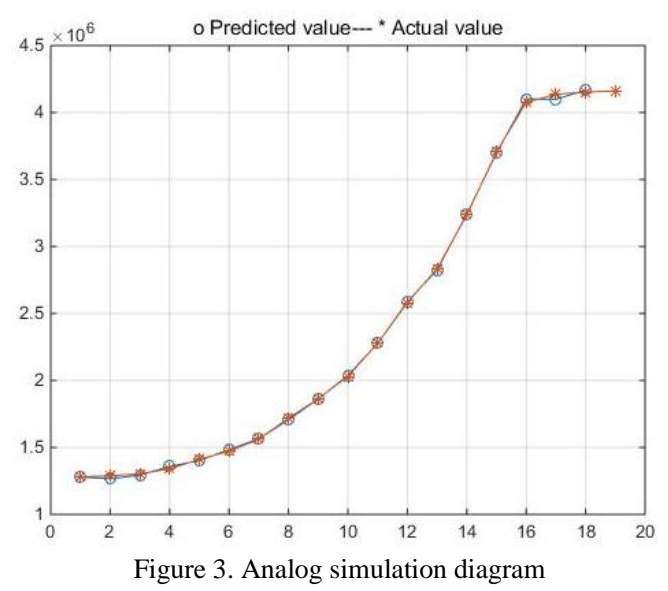

Figure 4 (a) shows that network training converges after 14229 iterations, with a minimum mean square error of 0.000099996. (b) indicates that the correlation coefficient $\mathrm{R}$ of the network training fitting is 0.99991 and that it has a good fitting effect. 


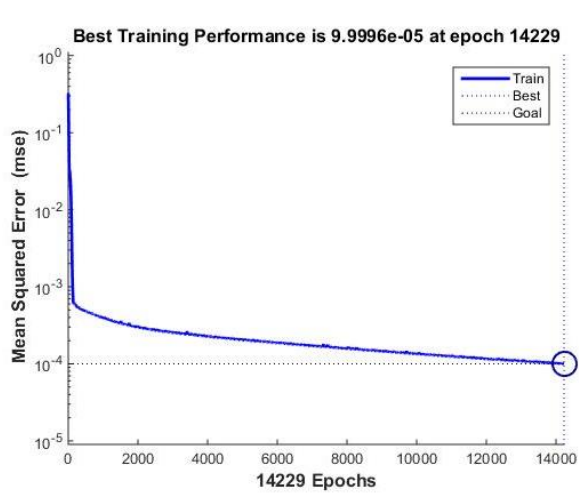

(a)

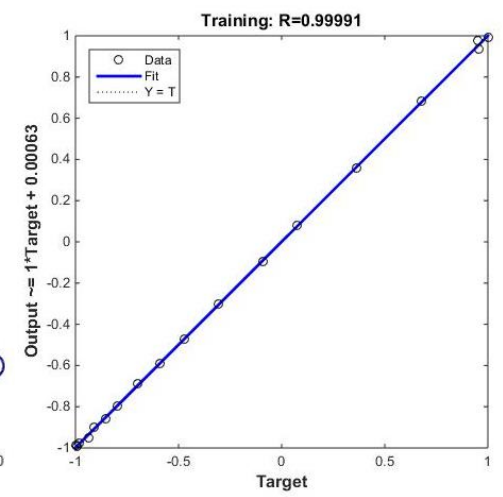

(b)

Figure 4. Mean square error and fitting correlation coefficient

According to the above analysis results, we can see that the simulation value, mean square error and fitting correlation coefficient in the output data of BP neural network have great effectiveness. However, compared with other methods, it has to be tested whether the BP neural network method has certain advantages in accuracy. Therefore, a linear regression is selected to do the next data comparison analysis. Then, we will choose the method that is more accurate to predict the future e-logistics demand between urban and rural areas.

\subsection{Analysis of Linear Regression}

In this paper, SPSS (23.0) is used for linear regression analysis. X1, X2, X3, X4, X5 and X6 are independent variables, and $\mathrm{Y}$ is a dependent variable. In addition, the data of indicators from 1997 to 2014 are the individual cases. After that, we import the relevant data into the software and gain the following output results.

Table 2. Model summary

\begin{tabular}{|c|c|c|c|c|}
\hline Model & R & R square & Adjusted R square & Std. error of the estimate \\
\hline 1 & $.999^{\mathrm{a}}$ & .999 & .998 & 50871.8362 \\
\hline \multicolumn{5}{|c|}{ a. Predictors: (Constant), X6, X1, X3, X2, X4, X5 } \\
\hline
\end{tabular}

The adjusted $\mathrm{R}$ square in Table 2 is 0.998 , which shows that the model can explain $99.8 \%$ of the data and that the model's fitting effect is pretty good.

\begin{tabular}{|c|c|c|c|c|c|c|}
\hline \multicolumn{2}{|r|}{ Modes } & Sum of square & df & Mean square & $\mathrm{F}$ & Sig. \\
\hline \multirow{3}{*}{1} & Regression & 19731122517015.023 & 6 & 3288520419502.504 & 1270.708 & $.000^{\mathrm{b}}$ \\
\hline & Residual & 28467380900.595 & 11 & 2587943718.236 & & \\
\hline & Total & 19759589897915.617 & 17 & & & \\
\hline \multicolumn{7}{|c|}{ a. Dependent Variable: Y } \\
\hline \multicolumn{7}{|c|}{ b. Predictors: (Constant), X6, X1, X3, X2, X4, X5 } \\
\hline
\end{tabular}

Table 3 is the result of variance analysis $(\mathrm{F}=1270.708, \mathrm{P}=0.000)$. This means that the model has notable statistical significance.

Table 4. Coefficients ${ }^{\mathrm{a}}$

\begin{tabular}{|c|c|c|c|c|c|c|}
\hline & \multirow{2}{*}{ Model } & \multicolumn{2}{|c|}{ Unstandardized coefficients } & \multirow{2}{*}{$\frac{\text { Standardized coefficients }}{\text { Beta }}$} & \multirow{2}{*}{$\mathrm{t}$} & \multirow{2}{*}{ Sig. } \\
\hline & & $\mathrm{B}$ & Std. error & & & \\
\hline \multirow{7}{*}{1} & (Constant) & 7690250.122 & 2040260.798 & & 3.769 & .003 \\
\hline & $\mathrm{X} 1$ & -.332 & .123 & -.117 & -2.691 & .021 \\
\hline & $\mathrm{X} 2$ & 10.260 & 5.341 & .222 & 1.921 & .081 \\
\hline & $\mathrm{X} 3$ & -58.383 & 18.064 & -.121 & -3.232 & .008 \\
\hline & $\mathrm{X} 4$ & -8287.182 & 2902.092 & -.473 & -2.856 & .016 \\
\hline & $\mathrm{X} 5$ & 43.588 & 10.824 & 1.097 & 4.027 & .002 \\
\hline & $\mathrm{X} 6$ & 7.589 & 3.207 & .363 & 2.366 & .037 \\
\hline \multicolumn{7}{|c|}{ a. Dependent Variable: Y } \\
\hline
\end{tabular}


Table 4 contains the estimated value and result of inspection from constants and regression coefficients in the regression equation $(\mathrm{a}=7690250.122, \mathrm{X} 1=-0.332, \mathrm{X} 2=10.26, \mathrm{X} 3=-58.383, \mathrm{X} 4=-8287.182, \mathrm{X} 5=43.588, \mathrm{X} 6=7.589)$. Hence, the expression of the linear regression equation model can be written out as follows.

$$
\mathrm{Y}=-0.332 * \mathrm{X} 1+10.26 * \mathrm{X} 2-58.383 * \mathrm{X} 3-8287.182 * \mathrm{X} 4+43.588 * \mathrm{X} 5+7.589 * \mathrm{X} 6+7690250.122
$$

Table 4 showed that the values of $\mathrm{P}$ corresponding to constant a, independent variables X1, X3, X4, X5 and X6 were less than 0.05 , which indicates that X1, X3, X4, X5 and X6 have a strong linear relationship with Y. Nevertheless, the P value of $\mathrm{X} 2$ is 0.081 , bigger than 0.05 . So, the significance level is not obvious, indicating that the linear relationship between $\mathrm{X} 2$ and $\mathrm{Y}$ may not be strong. In order to find out the reason and analyze the possible impact on the prediction of e-logistics demand in urban and rural areas, this paper will compare the data simulation results between the BP neural network model and linear regression model.

\subsection{Comparison and Prediction}

\subsubsection{Comparative Analysis}

In this paper, the simulation prediction value from the BP neural network model and linear regression model are compared with the actual value of e-logistics demand (Y) between urban and rural areas. Table 5 lists the absolute error and fractional error from the two models.

Table 5. E-logistics demand scale's error comparison of the predicted value and actual value from 1997 to 2015

\begin{tabular}{|c|c|c|c|c|c|c|}
\hline Year & \multicolumn{3}{|c|}{ BP neural network prediction model } & \multicolumn{3}{|c|}{ Linear regression prediction model } \\
\hline-- & Predicted value & Absolute error & Fractional error & Predicted value & Absolute error & Fractional error \\
\hline 1997 & 1280963.307 & 2745.306744 & 0.002147761 & 1278385.929 & 167.9289 & 0.000131377 \\
\hline 1998 & 1288554.962 & 21127.96159 & 0.016669963 & 1291545.967 & 24118.9673 & 0.019029867 \\
\hline 1999 & 1304002.416 & 10994.41592 & 0.008502976 & 1323054.813 & 30046.813 & 0.023237917 \\
\hline 2000 & 1339408.881 & -19273.11856 & -0.014185158 & 1326875.319 & -31806.6809 & -0.023409952 \\
\hline 2001 & 1411964.872 & 10178.87241 & 0.00726136 & 1352208.856 & -49577.1441 & -0.035367127 \\
\hline 2002 & 1471582.38 & -11864.62024 & -0.007998008 & 1453992.552 & -29454.4479 & -0.01985541 \\
\hline 2003 & 1561867.21 & -2624.790372 & -0.001677727 & 1528522.188 & -35969.8118 & -0.022991368 \\
\hline 2004 & 1717977.434 & 11565.43398 & 0.006777633 & 1773680.352 & 67268.35152 & 0.039420932 \\
\hline 2005 & 1864410.428 & 2344.42843 & 0.001259047 & 1921835.728 & 59769.72762 & 0.032098609 \\
\hline 2006 & 2030252.486 & -6807.513793 & -0.003341833 & 1994216.876 & -42843.12359 & -0.021031842 \\
\hline 2007 & 2277030.963 & 1208.963298 & 0.00053122 & 2278601.899 & 2779.89945 & 0.001221492 \\
\hline 2008 & 2580461.128 & -5475.871677 & -0.002117558 & 2567658.165 & -18278.8348 & -0.007068554 \\
\hline 2009 & 2833810.134 & 8588.133813 & 0.003039808 & 2852325.045 & 27103.04455 & 0.009593244 \\
\hline 2010 & 3235010.387 & -6796.613362 & -0.002096551 & 3293705.175 & 51898.17538 & 0.016009027 \\
\hline 2011 & 3704614.958 & 7653.958113 & 0.002070338 & 3703838.819 & 6877.8188 & 0.001860398 \\
\hline 2012 & 4076169.147 & -24266.8534 & -0.005918115 & 4015948.742 & -84487.25774 & -0.020604457 \\
\hline 2013 & 4136294.817 & 37394.817 & 0.009123135 & 4098409.651 & -490.34912 & -0.000119629 \\
\hline 2014 & 4153025.545 & -14270.45526 & -0.003424392 & 4188832.114 & 21536.11433 & 0.005167887 \\
\hline 2015 & 4161074.2 & -14811.79951 & -0.003546984 & 4110100.897 & -65785.1035 & -0.015753568 \\
\hline $\begin{array}{l}\text { Average } \\
\text { error }\end{array}$ & ---- & 400.5607956 & 0.000688259 & --- & -3679.253266 & -0.000970061 \\
\hline
\end{tabular}

As seen in Table 5, the BP neural network model is more accurate than the linear regression model. Specifically, the maximum relative error of the BP neural network model is 0.016669963 , while the maximum relative error of the linear regression model is 0.039420932. Similarly, in the case of absolute value, the mean error of the BP neural network model is 400.5607956 , and the average of the relative error is 0.000688259 , which is less than the corresponding error values of the linear regression model. Therefore, the simulation prediction value of the BP neural network model is closer to the actual value.

In Figure 5, (a) is the absolute error contrast line graph, and (b) is the relative error value contrast line chart. Clearly, the amplitude of absolute error and relative error from the BP neural network model is smaller than the linear regression model. Alternatively, the BP neural network model is more stable. In the preamble regression analysis, it is found that the significance level of X2 is not obvious. We infer that this may be because the linear relationship between $\mathrm{X} 2$ and $\mathrm{Y}$ is not strong. Theoretically, this is because the linear regression model has some shortcomings in solving the problem of a nonlinear variable relationship. Correspondingly, the BP neural network has the ability to deal with the relationship between linear and nonlinear variables. 


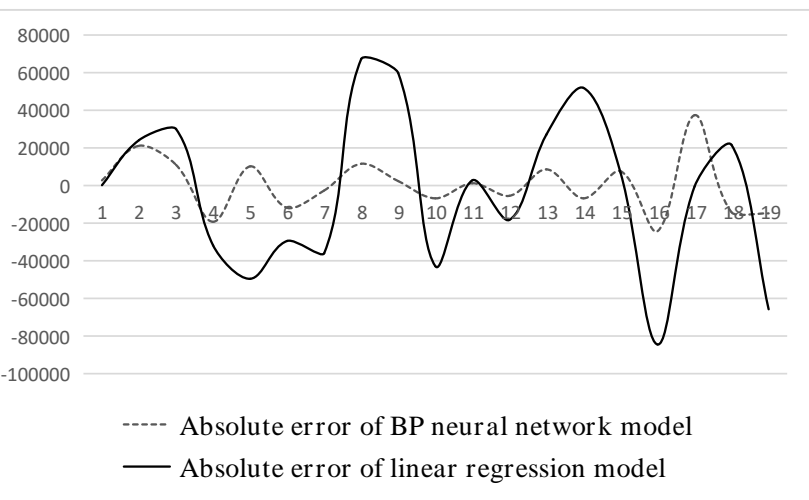

(a)

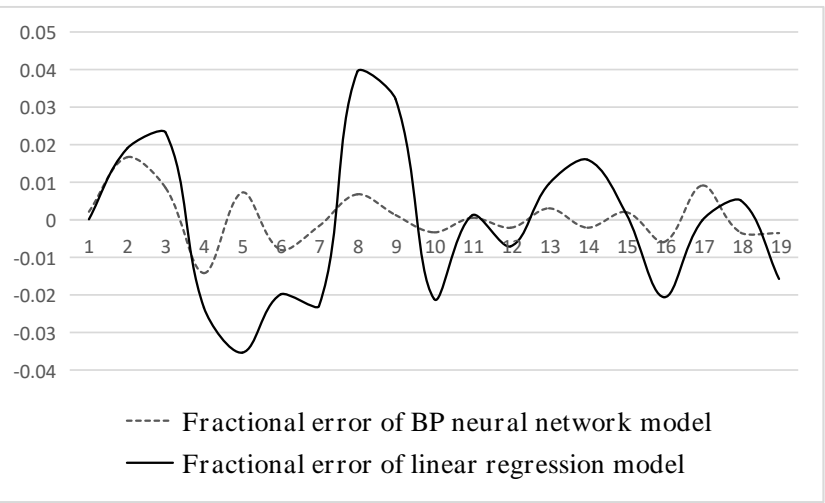

(b)

Figure 5. Error comparison graph

\subsubsection{Forecast of E-logistics Demand Scale in Urban and Rural Areas}

Figure 5 indicates that the BP neural network model is more accurate and stable than the linear regression model in the prediction of e-logistics demand scale in urban and rural areas. Accordingly, in this paper, three years of urban and rural elogistics demand is input into the BP neural network cycle prediction model. Meanwhile, in order to increase the prediction accuracy and stability, we repeated the operation 10 times, eventually taking the closest set of data to the average prediction results. Table 6 reveals the specific data results of the e-logistics demand scale in urban and rural areas from 2016 to 2020.

\begin{tabular}{|c|c|c|c|c|c|}
\hline Year & 2016 & 2017 & 2018 & 2019 & 2020 \\
\hline Forecast value of e-logistics demand scale (Ten thousand ton) & 4209070 & 4229680 & 4236500 & 4244570 & 4250250 \\
\hline Year-on-year growth rate $(\%)$ & 0.7946577 & 0.4896569 & 0.1612415 & 0.1904874 & 0.133818 \\
\hline
\end{tabular}

This paper takes the actual value of e-logistics demand scale from 1997 to 2015 and the forecast value of e-logistics demand scale from 2016 to 2020 as cardinality. According to the formula, year-on-year growth rate $=($ this year's value $/$ the last year's value of the same period) / the last year's value of the same period $* 100 \%$. We can get the year-on-year growth rate from 1998 to 2020 as shown in Table 7. Figure 6 illustrates that from 1998 to 2012, China's urban and rural e-logistics demand scale showed a rapid growth trend. The average year-on-year growth rate was $8.173679939 \%$. Whereas from 2013 to 2015, the demand scale of e-logistics in urban and rural areas gradually slowed down, and the average year-on-year growth rate dropped to $0.637410368 \%$. According to the value of the BP neural network cycle prediction model, from 2016 to 2020 , the average year-on-year growth rate of e-logistics demand scale in urban and rural areas was $0.3539723 \%$.

Table 7. Year-on-year growth rate of urban and rural e-logistics freight volume from 1998 to 2020

\begin{tabular}{|c|c|c|c|c|c|}
\hline Year & Year-on-year growth rate (\%) & Year & Year-on-year growth rate (\%) & Year & Year-on-year growth rate (\%) \\
\hline 1998 & -0.84422219 & 2006 & 9.39784089 & 2014 & 1.66864280 \\
\hline 1999 & 2.01834110 & 2007 & 11.7209115 & 2015 & 0.20612887 \\
\hline 2000 & 5.07916424 & 2008 & 13.6265051 & 2016 & 0.7946577 \\
\hline 2001 & 3.17248628 & 2009 & 9.25331901 & 2017 & 0.4896569 \\
\hline 2002 & 5.82549690 & 2010 & 14.7452129 & 2018 & 0.1612415 \\
\hline 2003 & 5.46328922 & 2011 & 14.0401326 & 2019 & 0.1904874 \\
\hline 2004 & 9.07131516 & 2012 & 10.9136937 & 2020 & 0.133818 \\
\hline 2005 & 9.12171269 & 2013 & 0.03745943 & -- & - \\
\hline
\end{tabular}

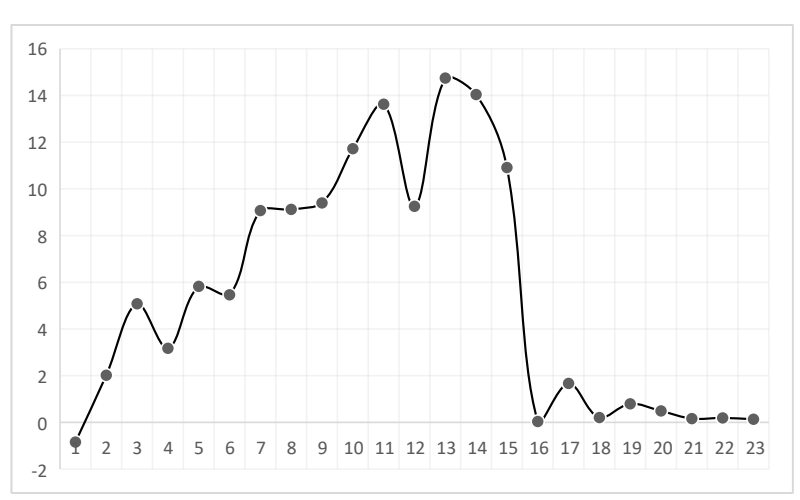

Figure 6. Year-on-year growth rate graph from 1998 to 2020 


\section{Findings and Discussions}

Based on the SCOR theoretical model and reference to previous studies, this paper selected 6 indicators to measure the urban and rural e-logistics demand scale. The historical data of the selected indicators is simulated using the BP neural network model, and the simulation data is compared by a linear regression model. By comparison, in this study, we find that the BP neural network is more stable and accurate than the linear regression in the simulation and prediction of data. So, this paper uses the BP neural network model to forecast China's e-logistics demand scale in urban and rural areas from 2016 to 2020. Accordingly, the year-on-year growth rate of e-logistics demand scale in urban and rural areas from 1998 to 2020 can be obtained. Throughout the above study, there are two major findings worthy of further discussion:

First, the research methods. In the simulation and prediction of data, the BP neural network model is more stable and accurate than the linear regression model. This finding is obtained by comparing the mean absolute errors and the average relative errors of the two methods. This is consistent with Rumelhart and McClelland's opinions that the BP neural network has the ability to deal with linear non-separable problems, which was proposed in the mid of 1980s. More precisely, the basic reason is that the hidden layer of the BP neural network uses the Sigmoid function as the transfer function, while the output layer uses the linear function as the transfer function. The Sigmoid function is a smooth and differentiable function with nonlinear amplification capacity. On the contrary, the linear regression analysis has some limitations in solving nonlinear problems.

Second, the content of the study. Through the analysis of the average year-on-year growth rate of e-logistics in urban and rural areas from 1998 to 2020, the development growth period of e-logistics demand in China's urban and rural areas is divided into two stages, as shown in Figure 7.

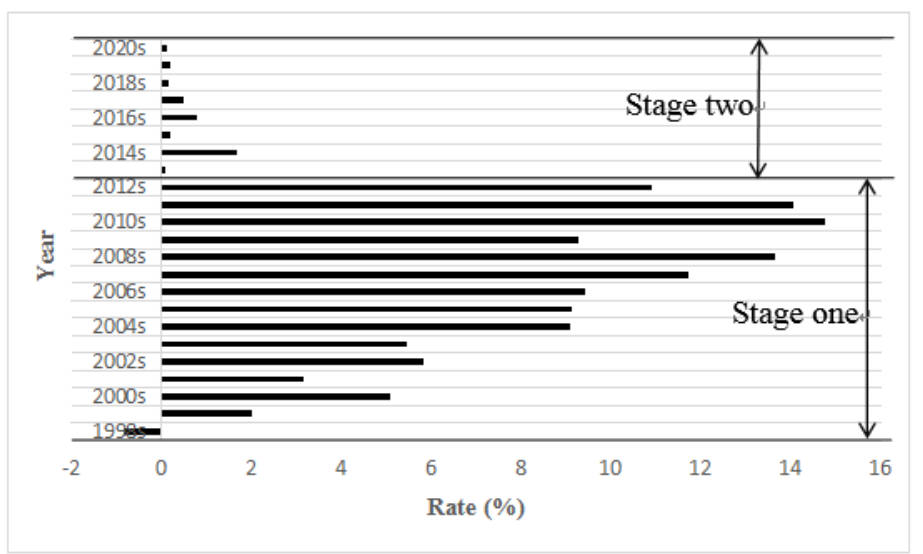

Figure 7. The development growth stages of e-logistics demand in urban and rural areas

Stage one is from 1997 to 2012. At this stage, the average year-on-year growth rate of e-logistics demand in urban and rural areas reached $8.173679939 \%$. This stage is a period of 20-30 years after China's reform and opening up. Also, it was from 1997 that China's e-commerce began to gradually develop and expand. Because of the support of government policies and the boost of e-commerce, the demand for e-logistics in urban and rural areas developed. However, in this historical period, the development of e-logistics in urban and rural areas also exposed many problems, such as a shortage of talent in e-commerce and logistics, imperfect policies and regulations, lack of management systems and mechanisms, backward infrastructure and low level of information. These further led to the high cost and low efficiency in the development of urban and rural elogistics. Because of this, the existence of these problems forced the transformation and upgrade of urban and rural e-logistics, and after this, China's urban and rural e-logistics development gradually entered the second stage.

Stage two began in 2013. Based on the analysis of the data in this paper, this period is likely to be between 2013 and 2020. Specifically, the average year-on-year growth rate of e-logistics demand scale in urban and rural areas is $0.637410368 \%$ from 2013 to 2015, and from 2016 to 2020, the average year-on-year growth rate of e-logistics demand scale in urban and rural areas is $0.3539723 \%$. The values of the two sets of data are relatively close and can be identified at the same stage.

The main reason is that, during this period, China's economic development entered a new normal state: structural reforms in the supply side deepened, and mobile payments, digital economy, sharing economy and other new economic development patterns continue to subvert the traditional e-commerce industry. The logistics industry continues to escalate. Certainly, it also benefits from the gradual maturity of intelligent logistics, cloud logistics platform, intelligent sorting car, unmanned aerial 
vehicle distribution and other new logistics technology. Therefore, at this stage, we no longer only pursue the growth rate of the e-logistics demand scale. In fact, we pay more attention to the reduction of cost, the promotion of efficiency, and the guarantee of quality and service.

\section{Contributions and Enlightenments}

With regard to the contributions, there are two points in this paper. The first is the inheritance and innovation of study methods. In the process of index selection, this paper refers to previous research and selection approaches of urban and rural logistics demand indicators. The SCOR theoretical model is first introduced in this study. We also compared the two methods of BP regression and linear neural network, and further confirmed the superiority of the BP neural network in solving non-linear problems. The second is the discovery of the research content. Based on the empirical analysis, the development stage of China's urban and rural e-logistics demand is divided into two stages from 1997 to 2020 . The division of these two stages has reliable data support. It is conducive to the verification of the effectiveness of historical policies and provides theoretical guidance for future policy formulation.

Predictably, there is some enlightenment for government, enterprises, consumers and farmers. First, in the formulation of macroeconomic policies for the development of e-commerce and logistics, the government should clearly illustrate the current development stage of urban and rural e-logistics in China. In addition, the government should rationally guide enterprises and farmers to make production according to the e-logistics demand scale, which is put forward by this paper. More importantly, the government should strengthen the legislation and supervision on the quality, safety, customer service and brand for e-commerce and logistics enterprises. Second, the e-commerce and logistics enterprises should turn the traditional production priority strategy into market demand and quality priority. Specifically, under the premise of reducing cost and improving efficiency, they should pay more attention to the promotion of the enterprise brand, the control of quality and safety, and the enhancement of serviceability. Third, consumers should actively participate in the review of online shopping and report unqualified products to the government. Fourth, a large part of the business of urban and rural e-logistics involves farmers. What's more important is that, on one hand, farmers are the producers and suppliers of agricultural products, and on the other hand, they are the consumers for industrial products. Thus, farmers should first rationally cultivate production according to the guidance of the government and market. Secondly, they should adhere to the bottom line of morality, abide by the principle of good faith, and achieve safe production and green supply. Finally, the farmers should also actively participate in the activities of industrial products "downstream" because it is conducive to the development of urban and rural e-logistics.

\section{Conclusions}

Meanwhile, this paper also has some limitations. One of them is the prediction of e-logistics demand scale in the next 5 years in China's urban and rural areas. Though the way of choosing index and data analysis is objective and scientific, this paper has no appropriate consideration of unpredictable risk factors, such as wars, natural calamities and financial crisis. Therefore, this may lead to a little deviation between the prediction results and the actual future value. The other one is related to the division method. This paper refers to the year-on-year growth rate of e-logistics demand scale in urban and rural areas as the division standard but references a different indicator. The division stages may also be different.

With regard to future research plans, first, the development stage of China's urban and rural e-logistics demand is divided into two stages from 1997 to 2020 . But for the second stage, there are lots of things we need to further clarify, such as what the government, enterprises, consumers and farmers should pay attention to and how to locate the focus of their work. Second, an event that is worth discussing is that the government, enterprises, consumers and farmers, as the main participants of ecommerce and logistics in urban and rural areas, should cooperate and coordinate in order to achieve the optimal system. In the future, our team will also pay more attention to solving more micro and systematic problems of e-commerce and logistics in urban and rural areas.

\section{Acknowledgements}

This work is supported by the National Social Science Foundation of China under Grant 15BGL201, the Project of Guangdong Think Tank Base under Grant 2018ZD1010, the Project of Guangzhou Think Tank Foundation under Grant 2018CZZK23, and the Basic Innovation Project for full-time postgraduate students of Guangzhou University in 2017 under Grant 2017GDJC-M25.

\section{References}

1. Y. Bai, Y. Li, X. Wang, et al. "Air Pollutants Concentrations Forecasting Using Back Propagation Neural Network based on Wavelet Decomposition with Meteorological Conditions," Atmospheric Pollution Research, vol. 7, no. 3, pp. 557-566, 2016 
2. S. Chen, M. Gan, Y. Tang, "Analysis of Predicting the Diversity Regional Logistics Demand based on SVR: The Case of Sichuan in China," Applied Mathematics \& Information Sciences, vol. 7, no. 2, pp. 645-651, 2013

3. K. L. Cheung, W. H. Hausman, "An Exact Performance Evaluation for the Supplier in a Two-echelon Inventory System," Operations Research, vol. 48, no. 4, pp. 646-653, 2000

4. H. Feng, J. L. He, Y. Liu, "Investigation and Analysis of Performance Evaluation System of Supply Chain Logistics Capability," Journal of Zhongnan University of Economics and Law, no. 1, pp. 113-118, 2014

5. C. C. Jane, "Performance Evaluation of Logistics Systems under Cost and Reliability Considerations," Transportation Research Part E, vol. 47, no. 2, pp. 130-137, 2011

6. M. I. Jia, "The Trend of Development and Informatization of Modern Logistics in China," Logistics Engineering \& Management, no. 5 , pp. $15-17,2015$

7. J. L. Li, T. Cheng, "Research on the Facilitation of E-commerce Technology Development on New-type Urbanization Construction in the Internet of Things Era," International Journal of $u$ - and e-Service, Science and Technology, vol. 8, no. 3, pp. 246-252, 2015

8. F. R. Limajunior, L. C. R. Carpinetti, R.W. Grubbström, “Combining SCOR® Model and Fuzzy TOPSIS for Supplier Evaluation and Management," International Journal of Production Economics, vol. 174, pp. 128-141, 2016

9. J. W. Li, G. Liu, "Boom Forecast Model based on BP Neural Network," Statistics \& Decision, no. 23, pp. 70-74, 2015

10. G. Q. Li, S. J. Liu, "Comprehensive Evaluation and Analysis on the Changing of Metropolis Logistics Demand-From the Empirical Data of the Seven Vice-Provincial City," Economic Geography, vol. 33, no. 8, pp. 104-108, 2013

11. J. T. Lalis, B. D. Gerardo, Y. Byun, "An Adaptive Stopping Criterion for Backpropagation Learning in Feedforward Neural Network," International Journal of Multimedia \& Ubiquitous Engineering, vol. 9, no. 8, pp. 149-156, 2014

12. L. H. Nie, "The Innovative and Standardized Development of E-commerce in China," China Business and Market, vol. 30, no. 6, pp. 52-57, 2016

13. K. I. Nikolopoulos, M. Z. Babai, K. Bozos, "Forecasting Supply Chain Sporadic Demand with Nearest Neighbor Approaches," International Journal of Production Economics, vol. 177, pp. 139-148, 2016

14. E. N. Ntabe, L. Lebel, A. D. Munson, et al. "A Systematic Literature Review of the Supply Chain Operations Reference (SCOR) Model Application with Special Attention to Environmental Issues," International Journal of Production Economics, vol. 169, pp. 310-332, 2015

15. Y. Sun, X. Bao, M. Cui, "Forecast of Regional Logistics Demand based on Set Pair Analysi," Industrial Electronics and Applications. IEEE, pp. 226-230, 2011

16. L. L. Si, W. Yn, G. J. Xu, "Logistics Demand Forecasting based on Improved Grey model" Computer Simulation, vol. 29, no. 6, pp. 167-192, 2012

17. K. S. Yogi, "Performance Evaluation of Reverse Logistics: A Case of LPG Agency," Cogent Business \& Management, vol. 2, no. 1,2015

18. B. Ya, "Study of Food Cold Chain Logistics Demand Forecast Based on Multiple Regression and AW-BP Forecasting Method on System Order Parameters," Journal of Computational and Theoretical Nanoscience, vol. 13, no. 7, pp. 4019-4024, 2016

19. S. G. Yang, X. L. Wang, "The application of Partial Least Squares and Grey Model in logistics demand forecast," Journal of Agrotechnical Economics, no. 7, pp. 105-111, 2010

20. H. Yin, L. Zhang, A. Lv, "Influencing Factors Analysis of Logistics Demand based on the Grey Correlation," Cota International Conference of Transportation Professionals, pp.346-352, 2016

Lijuan Huang graduated from Nanchang University in June 2006 and received her Ph. D. in Management Science Engineering. She is a professor at the School of Management, Guangzhou University, in Guangzhou, Guangdong, China. Her research areas include rural e-commerce and precision poverty alleviation.

Guojie Xie graduated from Hunan University of Technology in June 2016 and received his Bachelor's degree in Business Administration. He is a Master's graduate student at the School of Management, Guangzhou University, in Guangzhou, Guangdong, China. His research areas include rural e-commerce and rural logistics.

Dahao Li graduated from Guangzhou University in June 2017 and received his Bachelor's degree in Human Geography and Urban and Rural Planning. He is a Master's graduate student at the School of Management, Guangzhou University, in Guangzhou, Guangdong, China. His research areas include rural e-commerce and rural logistics.

Chunfang Zou graduated from the Finance and Economics University Of Jiangxi in December 2015 and received her Ph. D. in Management. She is an assistant professor at the School of Management, Guangzhou University, in Guangzhou, Guangdong, China. Her research areas include rural e-commerce and precision poverty alleviation. 